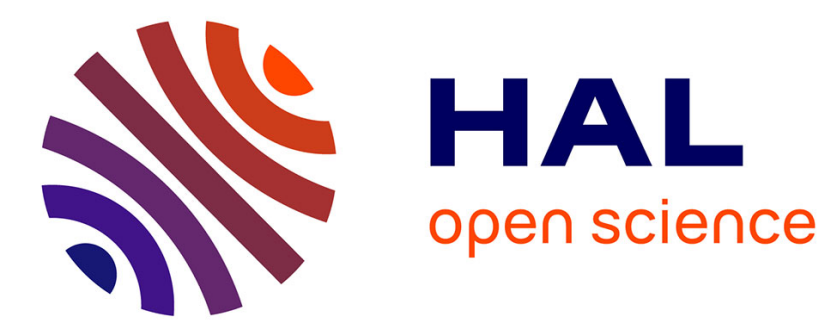

\title{
Absolute measurement of the abundance of atmospheric carbon monoxide
}

\author{
C. Brenninkmeijer, C. Koeppel, T. Röckmann, D. Scharffe, Maya Bräunlich, \\ Valerie Gros
}

\section{- To cite this version:}

C. Brenninkmeijer, C. Koeppel, T. Röckmann, D. Scharffe, Maya Bräunlich, et al.. Absolute measurement of the abundance of atmospheric carbon monoxide. Journal of Geophysical Research: Atmospheres, 2001, 106 (D9), pp.10003-10010. 10.1029/2000JD900342 . hal-03117189

\section{HAL Id: hal-03117189 \\ https://hal.science/hal-03117189}

Submitted on 8 Feb 2021

HAL is a multi-disciplinary open access archive for the deposit and dissemination of scientific research documents, whether they are published or not. The documents may come from teaching and research institutions in France or abroad, or from public or private research centers.
L'archive ouverte pluridisciplinaire HAL, est destinée au dépôt et à la diffusion de documents scientifiques de niveau recherche, publiés ou non, émanant des établissements d'enseignement et de recherche français ou étrangers, des laboratoires publics ou privés. 


\title{
Absolute measurement of the abundance of atmospheric carbon monoxide
}

\author{
C. A. M. Brenninkmeijer, C. Koeppel, T. Röckmann, D. S. Scharffe, \\ Maya Bräunlich, and Valerie Gros
}

Atmospheric Chemistry Division, Max Planck Institute for Chemistry, Mainz, Germany

\begin{abstract}
The main aspects of an absolute method for measurement of the mixing ratio of atmospheric carbon monoxide ( $\mathrm{CO}$ ) are presented. The method is based on cryogenic extraction of $\mathrm{CO}$ from air after oxidation to $\mathrm{CO}_{2}$ followed by accurate volumetric determination. Gravimetric measurement is used to determine the quantity of sample air processed. In routine operation the overall error can be kept below $1 \%$. Furthermore, the results of a laboratory intercomparison are analyzed. It is shown how offsets in the commonly applied analytical methods can occur and how these can seriously affect results obtained at the low concentration end ( $<100 \mathrm{nmole} / \mathrm{mole})$.
\end{abstract}

\section{Introduction}

The need to better know the budget of $\mathrm{CO}$ is reflected by the scale of international efforts in measuring and modeling the distribution and interactions of this ubiquitous chemically active trace gas [Novelli, 1999; Sanhueza et al., 1997; Moxley and Smit, 1998; Reichle et al., 1999; Connors et al., 1999; Bakwin et al., 1994; Novelli et al., 1998b, and the special issue of Chemosphere: Global Change Science, September 1999, 28 further papers]. Being the main reaction partner of hydroxyl $(\mathrm{OH})$, changes in $\mathrm{CO}$ affect $\mathrm{OH}$ and vice versa. Because of the central role of $\mathrm{OH}$ in the chemistry of the atmosphere, $\mathrm{CO}$ is an important trace gas.

Closely related to the cycle of $\mathrm{CO}$ is that of ${ }^{14} \mathrm{CO}$, which shares the same sinks, namely $\mathrm{OH}$ and soils. Given that the major origin of the ${ }^{14} \mathrm{C}$ in ${ }^{14} \mathrm{CO}$ is cosmogenic, and therefore independent of the sources of $\mathrm{CO}$ itself, ${ }^{14} \mathrm{CO}$ is of interest, even though it presents only a very small fraction of tropospheric $\mathrm{CO}$ ranging between $10^{-11}$ and $10^{-12}$. This is equivalent to only about 5 to 20 molecules per $\mathrm{cm}^{3}$ air STP. Nonetheless, ${ }^{14} \mathrm{CO}$ is a unique useful tracer for diagnosing $\mathrm{OH}$ distribution, large-scale hemispheric circulation, and fluxes from the stratosphere into the troposphere [Volz et al., 1981; Brenninkmeijer, 1993; Brenninkmeijer and Röckmann, 1998; Brenninkmeijer et al., 1992; Mak and Southon, 1998; Jöckel et al.; 2000, Quay et al., 2000]. Because determination of the abundance of ${ }^{14} \mathrm{CO}$ is based on that of $\mathrm{CO}$, the ability to make accurate and precise observation of $\mathrm{CO}$ is of direct relevance for ${ }^{14} \mathrm{CO}$ applications.

Of importance is how frequently, how precisely, and how accurately atmospheric $\mathrm{CO}$ should be measured. The question of frequency and precision is linked to the variability of $\mathrm{CO}$ which is dominated by its lifetime and influenced by localized sources. Generally the requirements are not as high as for $\mathrm{CO}_{2}, \mathrm{CH}_{4}$, and $\mathrm{N}_{2} \mathrm{O}$, and a $1 \%$ precision is considered adequate. The accuracy with which one has to know the mixing ratio of $\mathrm{CO}$ is rather fundamental because of the long term atmospheric changes. Besides the analysis of samples of air on site or in the laboratory, remote sensing via satellite borne optical detectors is rapidly gaining importance (e.g. Measurement of Air Pollution from Space (MAPS), Measurement of Pollution in the Troposphere (MOPITT), and Scanning Imaging Absorption Spectrometer for Atmospheric

Copyright 2001 by the American Geophysical Union.

Paper number 2000JD900342.

0148-0227/01/2000JD900342\$09.00
Chartography (SCIAMACHY)). Validation of data obtained by such remote sensing instruments is important.

Relevant is also the question whether there have been gradual changes in OH [Crutzen and Zimmermann, 1991; Krol et al., 1998; Prinn et al., 1995]. For establishing the causes, knowledge about changes in $\mathrm{CO}$ and also $\mathrm{CH}_{4}$ of similar precision is necessary. The same applies to ${ }^{14} \mathrm{CO}$, for which it may be particularly important to have accurate observations because of its unique potential as a long term diagnostic for changes the oxidative capacity of the atmosphere. Although one may never be able to model atmospheric $\mathrm{CO}$ (or ${ }^{14} \mathrm{CO}$ for that matter) with such a high degree of confidence that changes of the order of $1 \%$ would matter, there is no doubt that it would be unwise not to have accurate information at present. Even though it seems that an accuracy of $1 \%$ is feasible, there have been serious problems.

Most of the techniques for measuring $\mathrm{CO}$ are described by Novelli [1999]. The analysis of CO is almost exclusively based on relative methods, that is the comparison with standard mixtures of $\mathrm{CO}$, and the procuring and maintaining of traceable standards is difficult at times. Since the discovery of large differences between CO calibration scales used by different laboratories [Novelli et al., 1991], good progress in standardization has been made [Novelli et al., 1994; 1998a]. Primary gravimetric standard mixtures have been prepared and standards were prepared for laboratory intercomparison. [Novelli et al., 1994]. Two intercomparions have been organized by National Oceanic and Atmospheric Administration/Climate Monitoring and Diagnostics Laboratory (NOAA/CMDL), in 1994 and 1999. These "ring tests" enable direct comparison and allow the various laboratories to systematically follow and diagnose drifts in CO standards. This paper discusses an absolute method for the determination of $\mathrm{CO}$. Its results differ significantly from those of several other laboratories in the 50 to $100 \mathrm{nmole} / \mathrm{mole}$ range, and the possible reasons will be discussed.

\section{Experimental Methods}

\subsection{Extraction System}

The technique of Stevens [Stevens and Krout, 1972] for the isotopic analysis of $\mathrm{CO}$ is used. In essence, $\mathrm{CO}_{2}$ is removed from air, after which the $\mathrm{CO}$ content is oxidized and subsequently collected as $\mathrm{CO}_{2}$. The mixing ratio of $\mathrm{CO}$ is obtained by determining the mole fraction of $\mathrm{CO}_{2}$. The system (Figure 1) is an improved 


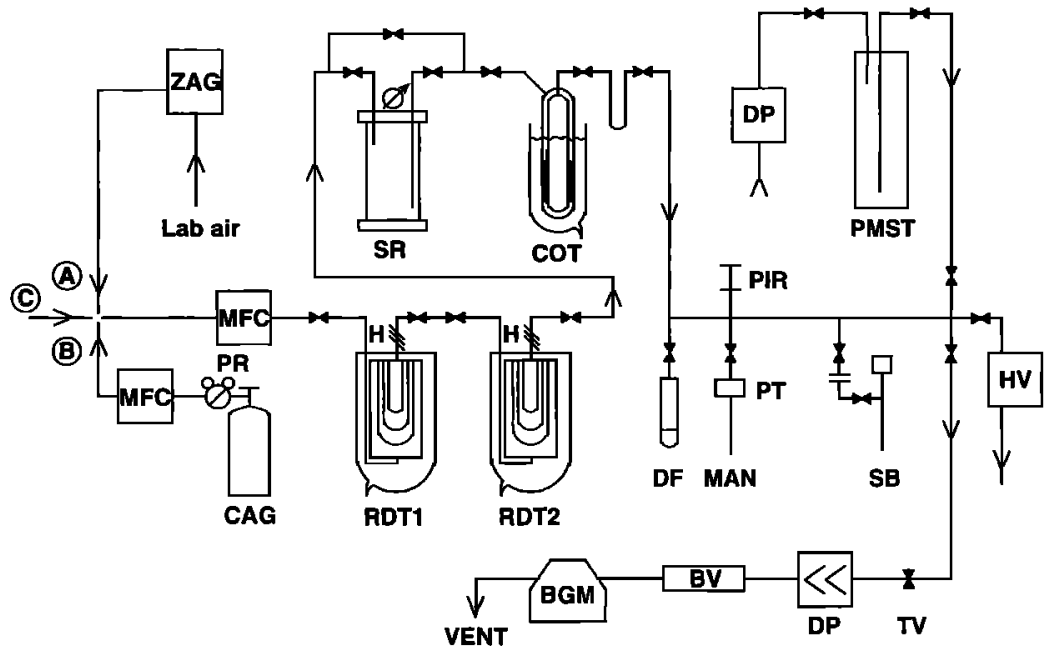

Figure 1. The CO extraction system. The following abbreviations were used: ZAG, zero gas generator; CAG, calibration gas; PR, pressure regulator; MFC, mass flow controller; RDT, Russian doll trap; SR, Schütze reactor; COT, collection trap; $\mathrm{H}$, heater; DP, diaphragm pump; PMST, purge molecular sieve trap; DF, drying finger; MAN, manometer; PT, pressure transducer; SB, sample bottle; PIR, Pirani vacuum gauge; HV, high vacuum pump stand; BV, buffer volume; TV, throttle valve; BGM, bellows gas meter.

version of a predecessor [Brenninkmeijer, 1993]. The main properties of the $\mathrm{CO}$ extraction procedure are as follows: (1) It is an absolute method in which the CO is quantitatively extracted; (2) it is an integrating method, which implies that by increasing the sample size through processing more air, the signal-to-noise ratio improves; and (3) the method has a low detection limit in the subnmole/mole range.

The flow of sample air ( $\left.5 \mathrm{~L} \mathrm{~min}^{-1} \mathrm{STP}\right)$ is regulated with a thermal mass flow controller (Hastings type HFC-202F). Condensable compounds are removed by two ultra efficient Russian Doll traps submerged in liquid nitrogen [Brenninkmeijer, 1991]. Such traps consist of stainless steel cylinders incorporating three concentric borosilicate glass fiber thimbles. Cooling at the outlet of these traps is prevented by sheathed thermocouples heater elements [Brenninkmeijer and Hemmingsen, 1988]. After removal of all $\mathrm{CO}_{2}, \mathrm{~N}_{2} \mathrm{O}$, and hydrocarbons ( $\mathrm{C} 3$ and higher), $\mathrm{CO}$ is oxidized to $\mathrm{CO}_{2}$ in a reactor (kept at $35^{\circ} \mathrm{C}$ ) filled with 0.81 of Schütze's reagent [Smiley, 1965], which consists of acidified $\mathrm{I}_{2} \mathrm{O}_{5}$ on silicagel. The reagent does not induce isotopic exchange and is very efficient in oxidizing $\mathrm{CO}$.

The small quantity of $\mathrm{CO}_{2}$ from the oxidation of $\mathrm{CO}$ is trapped at liquid nitrogen temperature in a glass Russian Doll trap [Brenninkmeijer and Röckmann, 1996]. Measurement of the quantity of $\mathrm{CO}_{2}$ produced is volumetric. The respective manometer consists of a volume isolated with a $5 \mathrm{~mm}$ bore O-ring glass valve [Brenninkmeijer, 1981] and is fitted with a piezo-resistive absolute pressure transducer (Institute of Geological and Nuclear Sciences (IGNS), model 9401). The volume being only $0.816 \mathrm{~cm}^{3}$ increases the pressure obtained and therefore the resolution.

\subsection{Extraction Procedure}

When not in use, the system is back-flushed with laboratory air cleaned using a $10 \mathrm{~L}$ reactor with $13 \mathrm{X}$ synthetic zeolite. The Schütze reagent is kept sealed off. Air samples are processed as follows. Back-flushing is terminated, and the two Russian Doll traps are submerged one after the other in liquid nitrogen. Sample air is admitted via the mass flow controller, and pumped away using the diaphragm pump (Vacubrand, type MZ4, O-ring set for improved sealing was used). At an initial flow rate of $1.5 \mathrm{~L} \mathrm{~min}^{-1}$ the system pressure reaches $50 \mathrm{hPa}$. The system is flushed for 10 min after which the air is shunted through the Schutze reactor. The system is flushed for $10 \mathrm{~min}$ and the collection trap cooled. After $1 \mathrm{~min}$, the glass fiber thimbles have reached liquid nitrogen temperature, and sample collection of $\mathrm{CO}_{2}$ commences. The integrator of the flow controller is initialized, and the gas meter readings are recorded. Subsequently, the flow is increased to $5 \mathrm{~L} \mathrm{~min}^{-1}$ upon which the pressure increases to $180 \mathrm{hPa}$. This is the highest possible pressure for optimizing the residence time of $\mathrm{CO}$ molecules in the Schütze reactor without freezing out oxygen in the traps.

After processing 350 to 4001 of air the flow is throttled to 1.5

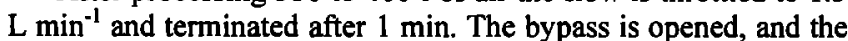
Schutze reactor is isolated. The inlet valve of the collection trap is closed. The process pump valve is closed at $5 \mathrm{hPa}$, and the valve to high vacuum pumping stage (Pfeiffer molecular drag pump) is opened to evacuate the collection trap. Subsequently, the $U$ tube is submerged in liquid nitrogen, its outlet valve is closed, and the large dewar surrounding the collection trap is removed. During 5 min the sample $\mathrm{CO}_{2}$ is distilled into the $\mathrm{U}$ tube. After further evacuation, the inlet valve of the $U$ tube is closed, and the sample $\mathrm{CO}_{2}$ is distilled into a small finger containing $\mathrm{P}_{2} \mathrm{O}_{5}$ for removing traces of water. Next the $\mathrm{CO}_{2}$ is transferred into a manometer by cryogenic distillation. After measuring pressure (typically 20 to 60 $\mathrm{hPa}$ ) and the temperature, the sample $\mathrm{CO}_{2}$ is distilled into a sample bottle for transfer to the mass spectrometer. The manual procedure can be automated by using methods developed before [Brenninkmeijer, 1983].

\subsection{Determination of the Quantity of Air}

Calculation of the mixing ratio is based on the volume of $\mathrm{CO}$ derived $\mathrm{CO}_{2}$ and the quantity of dry air processed. The quantity of air is determined using the electronic mass flow controller. This device is calibrated using a gas burette. Furthermore, a bellows type gas meter integrates the amount of air at the exhaust of the system. A buffer volume between the diaphragm pump and the meter reduces pressure pulses and improves the accuracy of the reading.

To ensure precise and accurate measurement of the amount of air, the cylinder containing the air to be processed is at times placed on an electronic balance. With a resolution and stability of 0.05 gram, the amount of air processed, which typically is $350 \mathrm{~L}$, 
can be measured to better than $0.1 \%$. There are three devices metering the amount of air processed (the correction for the amount of air $\mathrm{CO}_{2}$ extracted by the Russian Doll cleaning traps is too small to be significant), namely the integrating mass flow controller, the bellows gas meter, and the electronic balance. The most accurate and precise measurement is by the electronic balance.

\subsection{Volumetric Determinations of $\mathrm{CO}_{2}$}

The determination of the small amount of $\mathrm{CO}_{2}$ recovered is critical. The volume of the manometer, the pressure, and the temperature have to be known accurately. The electronic pressure transducer has in the range 0 to $200 \mathrm{hPa}$ a resolution of $0.01 \mathrm{hPa}$. The zero readings of this gauge over a period of 1 year ranged without adjustment around $0.1 \mathrm{hPa}$, with a standard deviation of less than $0.1 \mathrm{hPa}$. The day to day variability is typically $0.02 \mathrm{hPa}$, and before each measurement a zero reading is made for correction. The atmospheric pressure reading of the gauge is compared every day with that of a precise atmospheric pressure gauge (Paroscientific, Digiquartz 740). This instrument is extremely stable, has a resolution of $0.001 \mathrm{hPa}$, and is calibrated against the readings from the weather service. Furthermore, the linearity of the pressure sensor is better than $0.1 \%$. Note that the linearity in the actual volumetric measurement also assumes a constancy of the volume. To ensure reproducibility and minimal volume variations, a $5 \mathrm{~mm}$ Vacutap [Brenninkmeijer and Louwers, 1985] is used. Tests performed by repeated sealing of the manometer volume show that the error made is less than $0.1 \%$.

The volume of the manometer is established using a calibrated volume. This consists of a valve sealing off a short section of stainless steel tubing cut from a longer section. By several times filling this longer section with water and accurately weighing, the volume of the short section $\left(0.2442 \mathrm{~cm}^{3}\right)$ was determined with high accuracy. By filling this calibration volume with dry $\mathrm{CO}_{2}$ at a well-defined pressure (mostly near $1000 \mathrm{hPa}$ ) and temperature, and transferring this $\mathrm{CO}_{2}$ into the manometer accurate calibrations are made. To exclude measurement errors or mistakes, several approaches were used, which lead to the values in Table 1. In the first series of tests the calibration volume was filled with $\mathrm{CO}_{2}$ at near atmospheric pressure, cross-checked with the Digiquartz instrument. This $\mathrm{CO}_{2}$ was distilled into the manometer volume, and a pressure reduction of 0.3001 occurred, leading to the manometer volume given in the table. This value is subsequently corrected using the van der Waals equation. The end result is $816.1 \mu \mathrm{L}$. In the next series of tests the calibration volume was filled to lower starting pressures. In this instance the van der Waals correction becomes negligible; however, the starting pressure is not known as well as in the preceding case (no direct comparison at near atmospheric pressure is possible). The end result is $815.9 \mu \mathrm{L}$. This also confirms the high degree of linearity of the pressure transducers used.

The problem intrinsic to determining the manometer volume accurately is that internal volume measurement is difficult. Independent confirmation of the volume calibration was therefore carried out using external volume determinations. Three identical cylindrical stainless steel needles, with a diameter of $1.5 \mathrm{~mm}$, were accurately measured using a micrometer. By doing tests as described above using two or three needles inserted into the calibration volume (thus reducing its volume), a value of $815.1 \mu \mathrm{L}$ was obtained for the manometer. (In this determination the volume of the needles, provided they are identical, does not play a role.) Finally, by also using the calculated volume of the needles, a value of $816.8 \mu \mathrm{L}$ was obtained. The averaged value is $816.0 \pm 1 \mu \mathrm{L}$.

\subsection{Verification by Calibration Runs}

Regular calibration runs are performed injecting isotopically defined $\mathrm{CO}$ into a flow of air devoid of $\mathrm{CO}$ (zero air). A main reason for calibration is to establish the effect of the oxidation step on the oxygen isotopic composition of the $\mathrm{CO}_{2}$ produced. As the careful work by Stevens has shown, this oxidation solely adds an oxygen atom to the $\mathrm{CO}$ molecule, and there is no isotopic exchange with the $\mathrm{CO}_{2}$ produced [Brenninkmeijer, 1993; Brenninkmeijer and Röckmann, 1997]. In addition to the isotopic information, the calibration runs give a diagnostic of how well the system produces quantitative conversion and recovery of $\mathrm{CO}$ as is discussed below.

A certain quantity of $\mathrm{CO}$ is injected and exactly this should be recovered as $\mathrm{CO}_{2}$. The quantity of air processed during a calibration run is not of primary importance provided the zero air is devoid of $\mathrm{CO}$. The flow rates of both the zero air and $\mathrm{CO}$ injected can be varied thus providing different concentrations of $\mathrm{CO}$. The zero air is produced using heated reactors that contain $1 \mathrm{~L}$ of Hopcalite, or a Pt on aluminum-oxide catalyst (Merck). Temperatures of 100 to $200^{\circ} \mathrm{C}$ are applied. After oxidation of the $\mathrm{CO}$ content, the air is passed through a bed of $13 \mathrm{X}$ synthetic zeolite. This strips out water, $\mathrm{CO}_{2}$, and other impurities. With the zero air generators air without $\mathrm{CO}$ can be produced (less then $0.5 \mathrm{nmole} / \mathrm{mole}$ ) at flow rates of up to $20 \mathrm{~L} \mathrm{~min}^{-1}$. It is assumed that at $5 \mathrm{~L} \mathrm{~min}^{-1}$ the zero air contains less than $0.1 \mathrm{nmole} / \mathrm{mole} \mathrm{CO}$. Tests in which the molecular sieve of the zero air generator is replaced by Drierite (Hammond, Ohio), which does not remove $\mathrm{CO}_{2}$, do not show any difference in yield or isotopic composition. This is proof of the extreme efficiency of the two Russian Doll traps (combined $>99.99997 \% \mathrm{CO}_{2}$ removal). The small quantity of condensables $\left(\mathrm{CO}_{2}\right.$ and $\left.\mathrm{SO}_{2}\right)$ that is recovered in a zero run is subtracted from the quantity obtained for a sample.

Experience shows that the zero yield of the system increases when not in use. After one run the zero yield returns to a low level between 0.1 and $0.2 \mathrm{hPa}$. This is equivalent to approximately 0.25 to $0.5 \mathrm{nmole} / \mathrm{mole}$ for a $350 \mathrm{~L}$ air sample. A correction for this is applied, and the remaining uncertainty is less than $0.1 \mathrm{nmole} / \mathrm{mole}$. Thus, for air samples containing 50 to 200 nmole/mole $\mathrm{CO}$, the uncertainty in the blank correction introduces an error of 0.2 to $0.05 \%$.

For calibration, $\mathrm{CO}$ is not injected as pure $\mathrm{CO}$ gas, but as a mixture of $269 \pm 3 \mu \mathrm{mole} / \mathrm{mole} \mathrm{CO}$ in nitrogen gas. This mixture is metered using a thermal mass flow controller (Hastings HFC202A) which is occasionally calibrated with a gas burette. According to the supplier of the mixture (NZIG, Lower Hutt), it contained $271 \mathrm{ppm}$ by volume $\mathrm{CO}$; according to a bulk analysis carried out in the laboratory in New Zealand it contained $269 \pm 3$

Table 1. Determination of the Volume of the Manometer a

\begin{tabular}{lllll}
\hline & Standard & Lowe Pressure & $2-3$ needles & 2 Needles Absolute \\
\hline Ratio & $0.3001 \pm 0.0001$ & $0.2993 \pm 0.0001$ & $\mathbf{n} . \mathrm{a}^{\mathrm{c}}$ & $0.16795 \pm 0.0002$ \\
Volume, $\mu \mathrm{L}$ & $\mathbf{8 1 3 . 7 3 \pm 0 . 3}$ & $\mathbf{8 1 5 . 9 \pm 0 . 3}$ & $\mathbf{8 1 5 . 1 \pm 0 . 6}$ & $\mathbf{8 1 3 . 6 \pm 1}$ \\
Van der Waals corrected & $\mathbf{8 1 6 . 1 \pm 0 . 3}$ & $\mathbf{8 1 5 . 9 \pm 0 . 3}$ & $\mathbf{8 1 5 . 1 \pm 0 . 6}$ & $\mathbf{8 1 6 . 8 \pm 1}$ \\
\hline
\end{tabular}

The last row lists the final value after correction for the non-ideal gas behavior of $\mathrm{CO}_{2}$.

${ }^{b}$ In this determination the volume of the needles is irrelevant.

${ }^{c}$ Here not applicable. 


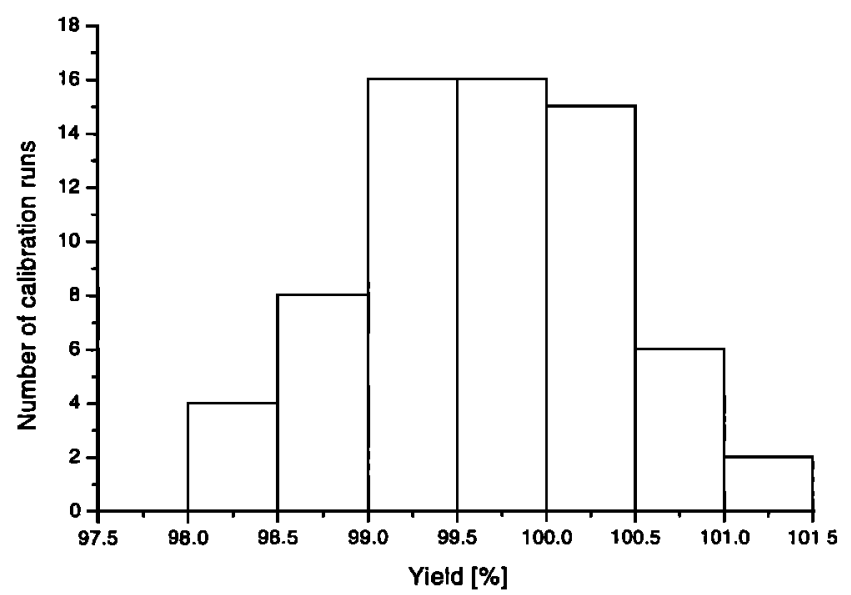

Figure 2. Frequency distribution for 67 calibration runs performed over 1 year.

$\mu$ mole/mole. On the basis of calibrations using this mixture, the yield of the extraction system is $99.8 \%$, with a standard deviation for an individual run of $0.7 \%$. These numbers are based on 67 determinations for September 1998 to October 1999. No calibration result has been omitted. Two persons have operated the system without this causing systematic differences. The frequency distribution obtained is symmetrical (Figure 2). The near $100 \%$ yield and $0.7 \%$ standard deviation prove independently that the CO can be determined with a precision and accuracy of about $1 \%$. This overall test involves conversion, trapping, releasing, and transferring.

\subsection{Tests of the Overall Efficiency}

In total efficiency the conversion of $\mathrm{CO}$ to $\mathrm{CO}_{2}$ is also critical. If this step is not quantitative, inserting a second Schütze reactor into the system and thus doubling the reaction time for $\mathrm{CO}$ will increase the yield. If, for instance, the yield is only $90 \%$, the addition of a second reactor boosts it to $99 \%$. A less cumbersome and effective alternative is the reduction of the pressure in the Schultze reactor during sample processing. Accordingly, by using two processing pumps in parallel the system pressure was reduced from the standard $180 \mathrm{hPa}$ to $50 \mathrm{hPa}$. This reduces the residence time of a $\mathrm{CO}$ molecule in the reactor from about $2 \mathrm{~s}$ to $0.5 \mathrm{~s}$. It can be shown that when the yield during the normal $180 \mathrm{hPa}$ conditions is $99 \%$, the yield should drop substantially to a mere $70 \%$. In contrast, during these experiments a drop in efficiency of less than $1 \%$ was observed from which it is calculated that the efficiency is over $99.9999 \%$. During these tests the pressure in the entire system was lowered, from which it is inferred that also the trapping of $\mathrm{CO}_{2}$ in the collection trap is nearly $100 \%$ efficient. That the yield would drop in the Schütze reactor, and that this would coin- cidentally be compensated by a concurrent increase in trapping efficiency of the collection trap, is unlikely. No change in isotopic composition was observed. Independently, the effect of lower levels of liquid nitrogen around the sample collection Russian doll trap has been investigated earlier [Brenninkmeijer and Röckmann, 1996]. Altogether these tests corroborate that the values of the main operating parameters are not in a critical range.

Despite the a priori linearity of the system, evidence for a small systematic deviation was obtained by analysis of data for duplicates. For a total of 22 cylinders with air samples collected at Spitsbergen [Röckmann and Brenninkmeijer, 1997], two subsamples of nominally 400 and $700 \mathrm{~L}$ were processed. It tums out that the mixing ratios established for the $700 \mathrm{~L}$ samples are systematically lower by $1.3 \%$. This is a puzzling effect because there is no obvious mechanism by which less $\mathrm{CO}_{2}$ would result for larger samples, or an error in the amount of air processed would be made. The cause of the effect is traced back to the efficiency of the Russian doll collection trap. Apparently, when the trap is cooled for a longer period of time, its efficiency drops. Because nearly all samples and calibrations are over a period of less than $80 \mathrm{~min}$, during which 350 to $400 \mathrm{~L}$ is processed, this effect had escaped observation during normal operating conditions. To determine the effect, normal calibrations were followed by delayed calibrations during which no calibration mixture was injected into the zero-air flow during the first hour. Under these conditions there was a drop of $2 \pm 0.5 \%$ in efficiency. These tests confirm the existence of a loss of efficiency when samples are processed over a longer period of time. The value of $2 \pm 0.5 \%$ will not be used to correct for the loss of efficiency. The 22 sample pairs of 400 and $700 \mathrm{~L}$ give the more accurate value of $1.3 \%$.

The cause for the abstruse loss in efficiency when sample air is processed over longer periods is not fully understood. The amount of $\mathrm{CO}_{2}$ seems too small to affect the properties of the large surface area of glass available for trapping it. Analysis of the composition of the air passing through the system did not show unexpected delays in one of the main components. A recent improvement to the procedure is to heat the collection trap to about $50^{\circ} \mathrm{C}$ during back flushing. After correcting the results for the 700 $\mathrm{L}$ samples for loss in efficiency, the duplicates can be used to assess the reproducibility of the system. A standard deviation for a single determination of only $0.5 \%$ is obtained. Thus, for routine operation, a random error of $0.5 \%$ can be guaranteed. This error is even smaller than that obtained for the calibration runs.

\subsection{Linearity Tests}

Deviations in linearity are investigated using two different linearity tests. Test one is based on injecting the calibration gas mixture at different rates. With the range of the mass flow controller being 0 to $10 \mathrm{~mL} \mathrm{~min}{ }^{-1}$ there is a practical lower limit of about $1 \mathrm{~mL} \mathrm{~min}$. . Below this the uncertainty in the injected quantity becomes too large. The results are shown in Table 2 . For each

Table 2. Linearity Test 1

\begin{tabular}{cccccc}
\hline Run $^{\text {a }}$ & $\begin{array}{c}\text { Injection Flow, } \mathrm{mL} \\
\text { min }^{-1}\end{array}$ & Mixing Ratio $^{\text {b }}$ & $\begin{array}{c}\text { Injected Quantity, } \\
\mu \mathrm{L}\end{array}$ & $\begin{array}{c}\text { Recovered Quantity, } \\
\mu \mathrm{L}\end{array}$ & $\begin{array}{c}\text { Yield, } \\
\%\end{array}$ \\
\hline 1600 & 1.0510 & 58 & 23.19 & 23.32 & 100.56 \\
1601 & 1.0510 & 58 & 23.27 & 23.34 & 100.30 \\
1602 & 2.0441 & 113 & 45.16 & 45.35 & 100.42 \\
1609 & 2.0448 & 113 & 45.20 & 45.54 & 100.75 \\
1603 & 3.0409 & 169 & 67.99 & 68.12 & 100.19 \\
1608 & 3.0280 & 169 & 66.81 & 66.75 & 99.91 \\
1599 & 3.9974 & 223 & 88.41 & 88.52 & 100.12 \\
1604 & 4.0205 & 223 & 89.95 & 89.63 & 99.64 \\
1605 & 6.3471 & 349 & 139.71 & 139.92 & 100.15 \\
1606 & 8.0916 & 446 & 178.42 & 178.05 & 99.79 \\
1607 & 9.8738 & 544 & 217.58 & 215.76 & 99.16 \\
\hline
\end{tabular}

${ }^{a}$ October 1998.

${ }^{\mathrm{b}}$ Nominal mixing ratios in nmole/mole related to $400 \mathrm{~L}$ sample air. 
setting of the calibration gas mass flow controller it was calibrated against a gas burette with a piston sealed by a mercury ring. At a flow rate of $5 \mathrm{~L} \mathrm{~min}^{-1}$ STP zero air, and a total of $400 \mathrm{~L}$ air, the equivalent mixing ratio varied from about 60 to $550 \mathrm{nmole} / \mathrm{mole}$. The yield obtained was $100.1 \%$ with a standard deviation for an individual measurement over the entire range of $0.45 \%$. The four duplicate determinations agree well within $0.4 \%$. A linear least squares fit to the data give for the recovered quantity gives $y=$ $0.9927 x+0.52$ nmole/mole $\left(r^{2}=0.99996\right)$. The data suggest a small drop in efficiency. At $544 \mathrm{nmole} /$ mole the yield is $1 \%$ below that obtained for the lower concentrations. Furthermore the yield is higher than that obtained for the calibration runs $(99.8 \%)$. The calibration runs are performed at nominally $200 \mathrm{nmole} / \mathrm{mole}$, for which the linear regression gives $99.5 \%$. There are no significant discrepancies between the results.

Linearity test 2 is based solely on the duration of the injection period at a constant setting of $2.0 \mathrm{~mL} \mathrm{~min}$. This test checks the linearity in the low nmole/mole range up to $300 \mathrm{nmole} / \mathrm{mole}$. Calibration gas was passed through a three- way valve into the zero-air flow allowing a rapid switching between waste and injection position. Injections at a flow of $2.0 \mathrm{~cm}^{3} \mathrm{~min}^{-1}$ were performed for $5 \mathrm{~min}$ (with increments of $10 \mathrm{~min}$ ) to a maximum period of $120 \mathrm{~min}$. The minimum equivalent effective concentration was therefore only approximately $6.5 \mathrm{nmole} / \mathrm{mole}$ for the equivalent of $400 \mathrm{~L}$ of air processed. Figure 3 shows a good linearity for up to about $60 \mathrm{hPa}$, and a very small random error. Applying a linear regression, excluding the upper two data points gives $y=1.0871 x$ $+0.2214 \mathrm{hPa}$. The standard deviation for a single determination is $0.4 \%$. Using this formula, the deviations for the two highest concentrations are 0.4 and $1.4 \%$ respectively. The test suggests a small drop in efficiency when air is processed over long periods of time. This is equivalent to the effect noted for the processing of the 400 and $700 \mathrm{~L}$ subsamples of the air cylinders and for the extended calibration run. The effect is not of relevance for the routine conditions. Test number 2 is not the exact equivalent of the injection of, for instance, $7 \mathrm{nmole} / \mathrm{mole}$ over the full period of sample processing. It does however establish the linearity of the system in the important low concentration range.

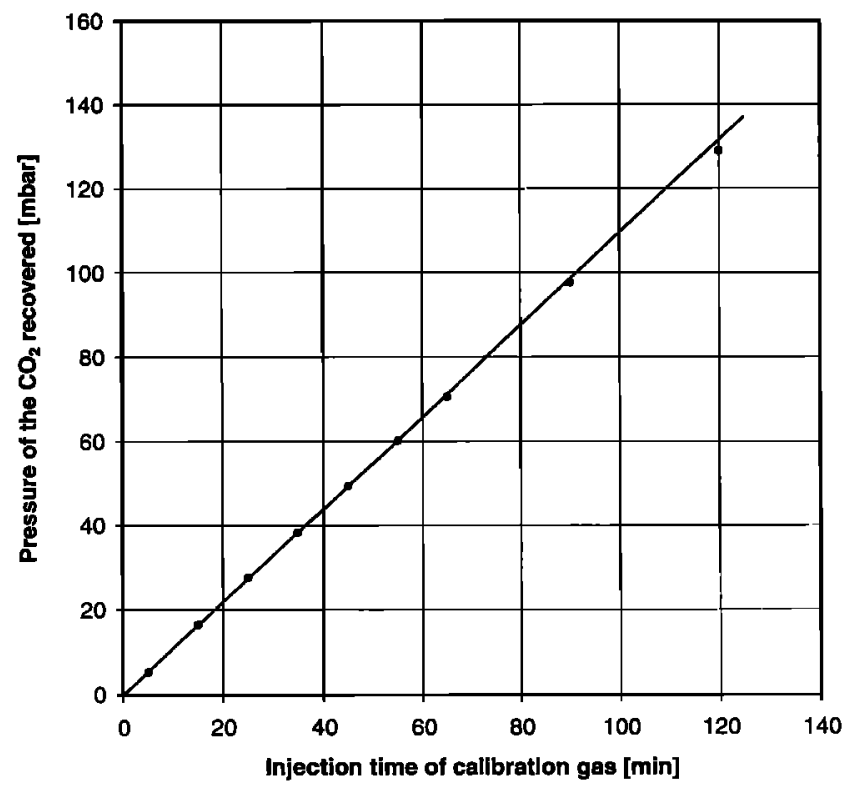

Figure 3. Linearity test 2 showing the pressure recorded in the manometer against the duration of the calibration gas injection at a flow rate of $2 \mathrm{~cm}^{3} \mathrm{~min}^{-1}$. The nominal equivalent concentration range is approximately 7 to $260 \mathrm{nmole} / \mathrm{mole}$.
Because Russian doll traps are efficient to a degree that can cause a gas chromatographic delay for $\mathrm{CO}$ passing through [Brenninkmeijer and Röckmann, 1996], and because the $1 \mathrm{~L}$ Schutze reactor itself in effect is a gas chromatography column, the speed with which a pulse of $\mathrm{CO}$ passes through the system was measured. $\mathrm{CO}$ at $8 \mathrm{~cm}^{3} \mathrm{~min}^{-1}$ was injected only during the very last $5 \mathrm{~min}$ of a run. The corresponding yield was $99 \%$ which assures that there is no significant delay or retention of $\mathrm{CO}$. The tests consistently confirm the high linearity, quantitative yields, and high reproducibility. One remaining question is whether it is pure $\mathrm{CO}_{2}$ that is collected. Mass spectra recorded at high amplification confirm purity of the sample collected.

A source of interference could be the oxidation of trace gases other than $\mathrm{CO}$ to $\mathrm{CO}_{2}$ in the Schutze reactor. This was tested by Stevens and Krout [1972] and is a negligible source of interference for normal air samples. Generally for the lower $\mathrm{CO}$ mixing ratios in remote air, concurrent nonmethane hydrocarbon mixing ratios are also lower. Tests based on the injection of $\mathrm{C}_{2} \mathrm{H}_{4}$ into calibration or zero air has no effect. Injection of $100 \mu \mathrm{mole} / \mathrm{mole} \mathrm{CH}_{4}$ does not change the amount of $\mathrm{CO}_{2}$ recovered, or its isotopic composition. Higher hydrocarbons ( $>\mathrm{C} 3$ ) are effectively trapped by the Russian doll traps and are present at very low concentrations only.

\subsection{Accuracy and Precision}

Estimated and measured random errors for the $50 \mathrm{nmole} / \mathrm{mole}$ level and processing $350 \mathrm{~L}$ of air are as follows: blank correction $0.2 \%$, pressure reading $0.3 \%$, temperature of $\mathrm{CO}_{2}$ sample in the manometer $0.3 \%$, and quantity of air $0.1 \%$.

The combined random error therefore is approximately $0.5 \%$. This can be compared with the independently determined value for the measured standard deviation of $0.5 \%$ which is based on duplicates. The precision obtained therefore is $0.5 \%$. For 200 nmole/mole this value improves to about $0.4 \%$.

Estimated values for the maximum systematic error are as follows: Quantity of air $0.2 \%$ and quantity of sample $\mathrm{CO}_{2} 0.3 \%$. The maximum deviation is thus $0.5 \%$. This can be compared with the independently determined value using the calibration runs of $0.2 \pm 1 \%$ deviation.

\section{Laboratory Intercomparison Tests}

\subsection{Analysis and Evaluation of the 1993-1995 Laboratory Intercomparison}

Over more than 10 years thorough work has been carried out to continuously improve the quality of $\mathrm{CO}$ measurements [Novelli et al., 1994]. Ring tests which are laboratory intercomparisons in which laboratories analyze subsamples of air from the same suite of cylinders help to compare data [Novelli et al., 1998a]. It is important not only to compare scales but also to understand the differences. A predecessor of the present system [Brenninkmeijer, 1993] was used in the 1994-1995 ring test [Novelli et al., 1998a]. Four cylinders with nominally $50,100,150$ and 200 nmole/mole were analyzed at the National Institute of Water and Atmospheric Research (NIWA), New Zealand in 1994. Because it was considered that by withdrawing as much as $350 \mathrm{~L}$ of air from the cylinders the $\mathrm{CO}$ concentration might be somehow affected, thus possibly spoiling the results of other laboratories later in the test sequence, it was decided to use the NIWA gas chromatograph (GC) system equipped with a reducing gas analyzer. Therefore the results could not be as precise as they would have been with direct analysis by extraction.

The GC was calibrated using the extraction system and a set of 10 cylinders with $C O$ values from 50 to over $200 \mathrm{nmole} /$ mole. The response of the GC system with reducing gas analyzer was not 


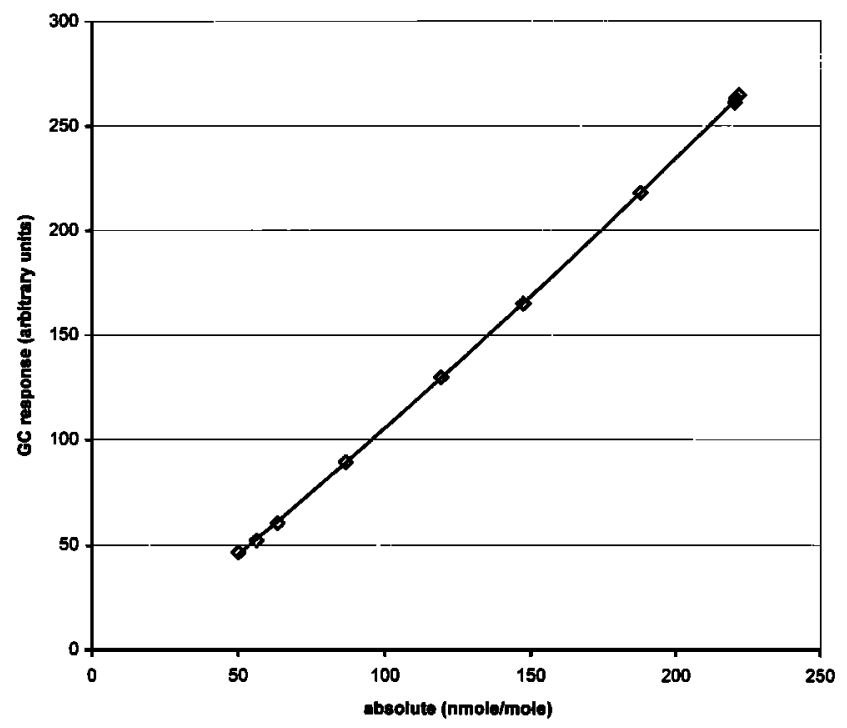

Figure 4. The calibration with quadratic least squares fit of the NIWA CO gas chromatograph in 1994 using 10 cylinders assayed by the absolute method.

linear. Furthermore, an air sample with a CO mixing ratio of 3.7 nmole/mole did not give a chromatography peak that could be integrated. The response of the GC systems with reducing gas analyzers is not always linear and may vary depending on the operating conditions. The results are shown in Figure 4. The scatter of the individual data points relative to the quadratic least squares fit is less than $1 \%$.

Table 3 shows the ring test results [Novelli et al., 1998a]. The mixing ratios relative to the NOAA-CMDL scale differ by $3 \%$ at the high end to $8 \%$ at the $50 \mathrm{nmole} / \mathrm{mole}$ level. In Figure 5 all results except those from INPE and HKP which showed rather large deviations (for acronyms, see Novelli et al. [1998a]) are plotted against the NIWA data as percentage deviation.

Several inferences that may improve the understanding of the differences will be made. CMDL, the Common Wealth Scientific and Industrial Research Organization (CSIRO), and NASA used the GC technique and the CMDL scale. NASA agrees fairly well with the NIWA values, but CMDL and CSIRO do not. The latter two are mutually consistent, and their results suggest that the NIWA values have an increasingly positive bias with decreasing concentration, for brevity referred to here as "the trend". IFU and CSIR, both using a mutual scale, and the GC technique, closely confirm the trend. Therefore one almost cannot escape but one conclusion. The NIWA values must be wrong, and this explains the trend. But is this correct? Not necessarily, because this also depends on whether the IFU scale used was independent of the CMDL scale. Both scales have a history of intercomparisons. Consequently, there may be no independent proof that the NIWA values are wrong.
What seems to cast some doubt on the NIWA data is that $\mathrm{AL}$ using the gas filter correlation technique (GFC) and National Institute of Standards and Technology (NIST) standards, seems to confirm the trend. Indeed, if the AL values are based on an independent scale and technique, the trend is confirmed independently, and the NIWA values must be in error. However, the UMD results, which also used GFC and NIST standards contradict the existence of the trend. Actually, both NASA and UMD do have very similar results, despite the use of different techniques and different standards. Admittedly their agreement at the 50 nmole/mole level is not as close as for the other three values, but with the GFC technique larger errors occur in the lower reaches, and these are also given. However, because UMD and NASA use independent scales and independent techniques, their results give support for the NIWA data showing an opposing trend.

From the available information it is not possible to retrospectively assess which values are correct. The results of the absolute method do not necessarily appear more correct. For better understanding the causes for the observed deviations a model based on the applied metrology is used. The NIWA data are used as reference; this is a working hypothesis. Consider the GC and GFC techniques. The GC technique suffers from two deficiencies. One is that the detector response is not always linear. This effect will not be considered here. The second problem is that the detection limit is not zero. When air containing only a few nmole/mole is injected, there may be no chromatography peak that can be integrated for determining a signal. The gas filter correlation (GFC) technique is intrinsically linear, but suffers from a worse signalto- noise ratio. Several laboratories have improved these instruments, yet even then, air containing a few nmole/mole $\mathrm{CO}$ cannot be assayed accurately. Thus both techniques cannot directly determine whether an air sample is free from $\mathrm{CO}$ at the nmole/mole level. The other problem is the familiar one that both techniques are indirect, and depend on the comparison of the system response with that for standards.

The errors introduced by offset and calibration errors in systems based on standards can be calculated. It is assumed for the present discussion that the assumed or measured mixing ratio " $a$ " is related to true or real value " $r$ " and the offset of the detector " $z$ " via $a=c r+z$. The relative error is $\Delta=\mathrm{a} / r-1=(c-1)+z / r$. In the next case the effect of errors in standards is addressed. Standards can be produced with great accuracy, based on gravimetric procedures. In these, uncertainties in the degree of dilution can be minimal. Another option is dynamic dilution, where the dilution errors may be larger, but often still acceptable. For reaching the low mixing ratios dilution with zero air or gas is applied. The point is that a large amount of air is added to lower the mixing ratio. Therefore the $\mathrm{CO}$ content of the dilution gas must be in the sub-nmole/mole range. If a high degree of dilution is needed, a residual CO level of $0.5 \mathrm{nmole} / \mathrm{mole}$ will lead to approximately the same bias of the diluted concentration produced. At the $\mathbf{5 0}$ nmole/mole level this would induce an error of $1 \%$. It is assumed for the present discussion that a standard is available with an actual mixing ratio " $s$ ". The assumed mixing ratio is, however, $c s$

Table 3. Results for Two Laboratory Intercomparisons

\begin{tabular}{cccccc}
\hline \multicolumn{2}{c}{ 1993-1995 Ring Test } & \multicolumn{3}{c}{$1998-1999$ Ring Test } \\
\cline { 4 - 6 } $\begin{array}{l}\text { NIWA gas chromato- } \\
\text { graphy/absolute }\end{array}$ & NOAA-CMDL & & MPI-C absolute & \multicolumn{1}{c}{$\begin{array}{l}\text { MPI-C gas } \\
\text { chromatograpy }\end{array}$} & $\begin{array}{l}\text { NOAA-CMDL } \\
1999^{\mathrm{b}}\end{array}$ \\
\hline 56.1 & 51.5 & & 51.8 & $52.1(0.5)^{\mathrm{c}}$ & $45.0(0.9)^{\mathrm{c}}$ \\
102.7 & 97.6 & & 98.8 & $98.9(1)$ & $91.6(0.9)$ \\
154.1 & 147.7 & 151.4 & $149.5(1.5)$ & $147.1(1.4)$ \\
204.5 & 198.0 & & 183.4 & $182.3(2)$ & $183.6(1.8)$ \\
& & 350.7 & $351.4(7)$ & $355.7(6)$ \\
\hline
\end{tabular}

\footnotetext{
${ }^{\mathrm{a}}$ Units are nmole/mole.

${ }^{b}$ P. Novelli (personal communication, 1999).

${ }^{\mathrm{C}}$ Uncertainty.
} 


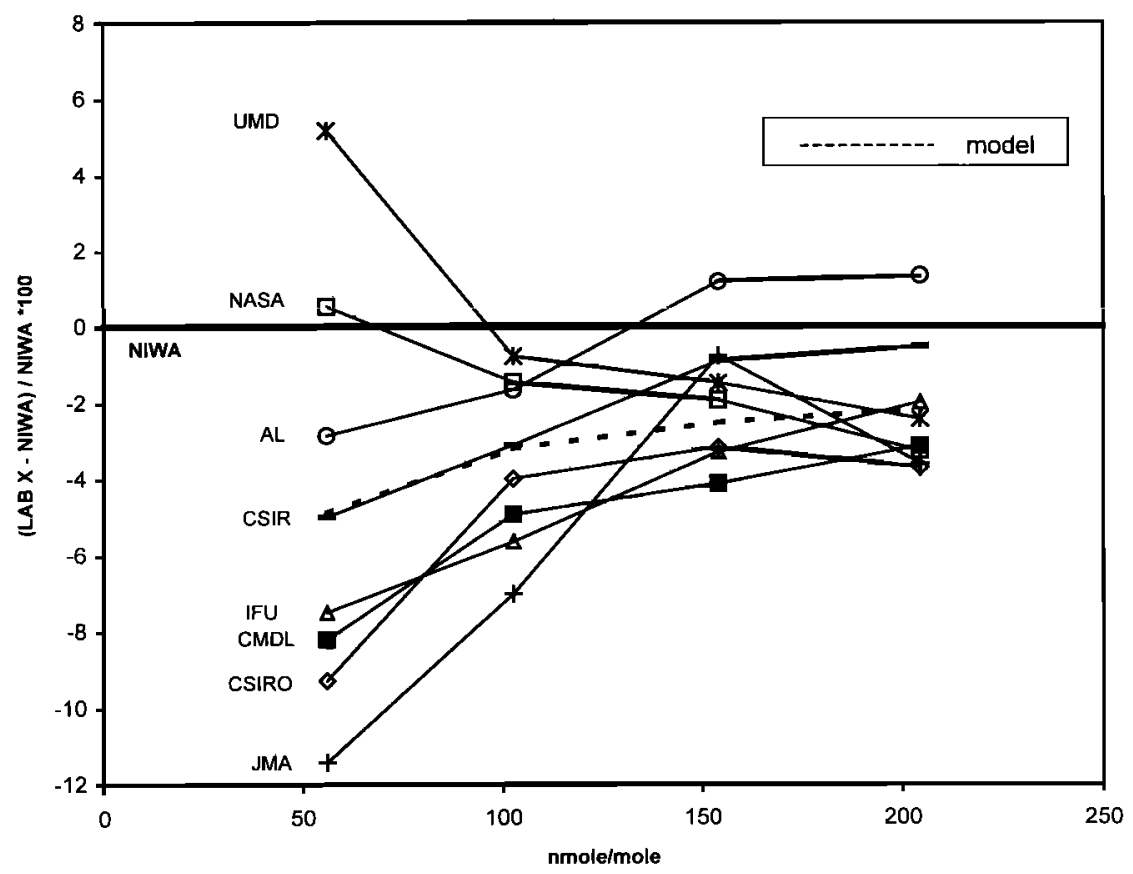

Figure 5. The results of the 1994-1995 ring test, plotted as the percent deviation relative to the NIWA data. The curve shown is based on $\mathrm{c}=0.989$ and $\mathrm{z}=-2.2 \mathrm{nmole} / \mathrm{mole}$ (see text). For the laboratory identifiers, see Novelli et al., 1998a.

nmole/mole. Further, it is assumed that the air for dilution is assumed to have 0 nmole/mole although it actually contains " $z$ " nmole/mole. This leads, for the standard made by dilution of a factor " $f$ ", to the assumption $a=f c s$. The real mixing ratio is, however, $r=f s+(1-f) z$. The resulting error is $\Delta=a / r-1=(c-1)$ $+z / r$. This error in the standards causes the same error for sample values. A third possibility for introducing systematic errors is that $\mathrm{CO}$ is gradually produced in a set of standards stored in cylinders. This is a common problem, and in the simplest case $\mathrm{CO}$ would grow at constant and identical rates in all cylinders irrespective of the $\mathrm{CO}$ concentration. This leads to a similar expression as for the two cases considered.

What becomes apparent from inspection of Figure 5 is that nearly all curves exhibit the hyperbolic characteristic of the expression derived above. The differences between the laboratories can be expressed in terms of offsets and calibration differences. At low values the offset becomes a dominant source of error. These deviations between the laboratories can also be gleaned from the tabulation by Novelli et al., [1998a] based on quadratic equations comparing all institutes to the NOAA scale. In Figure 5, NASA and UMD have curves that show an increasing positive deviation. CMDL, CSIRO, AL, JMA, and IFU together with CSIR show an increasing negative relative deviation towards the low concentrations. The curves most probably represent either the effect of bias in calibration and the existence of an offset, or the use of a nonzero dilution gas and a deviating value for the gas that was diluted, or the growth of $\mathrm{CO}$ in cylinders with standard mixtures.

The results from NIWA will now be compared with the average values of the other laboratories. At the nominal value of 200 nmole/mole the deviation between NIWA and the average is 4.4 nmole/mole, or $2.2 \%$. For calculating the averages, the values in Table 3 [Novelli et al., 1998a] are used without weighting the individual errors. Only the last CMDL value and one of the values submitted by CSIRO were used. HKP and INPE results were omitted. Because some scales are linked, this average is biased. Despite this, the most probable conclusion would be that the NIWA data at nominally $200 \mathrm{nmole} / \mathrm{mole}$ were $2.2 \%$ too high. At the lowest mixing ratio near $50 \mathrm{nmole} / \mathrm{mole}$, the average value is $53.3 \mathrm{nmole} / \mathrm{mole}$, which is $5.0 \%$ below the NIWA value. For cal- culating the average value, the second value submitted by CSIRO has been used, otherwise the same criteria apply as before. Using the equations derived above gives $z=-2.2 \mathrm{nmole} / \mathrm{mole}$ and $c=$ 0.989 as offset and calibration error, respectively, for the average compared to NIWA.

Without further information no further conclusions can be drawn. On the basis of the previous sections on the absolute method, it would seem that a plausible scenario is that NIWA had an error in the $200 \mathrm{nmole} /$ mole range of about $2 \%$. This for instance could be the result of a wrong calibration of the gas meter. If this applies, it still does not explain the higher values in the $\mathbf{5 0}$ nmole/mole range. In view of the low detection limit of the absolute method, and the high linearity, a conclusion would be that the average of the other laboratories is too low by a several nmole/mole. For a direct comparison between NIWA and the NOAA scale, this would mean that in the $50 \mathrm{nmole} / \mathrm{mole}$ range, the NOAA value was $3.5 \mathrm{nmole} / \mathrm{mole}$ too low in 1995 .

\subsection{The 1998-1999 Laboratory Intercomparison}

The second ring test involved two circuits of laboratories and two sets of cylinders. One set of cylinders with nominal values from 50 to 350 nmole/mole was made available to the Max Planck Institute for Chemistry. This time, in contrast to the first comparison in New Zealand, the mixing ratio for each cylinder was directly determined by processing $400 \mathrm{~L}$ of air from each cylinder with the system described. This volume of air was less than $10 \%$ of the cylinder's content.

It was also decided to additionally perform gas chromatographic determinations with a reducing gas analyzer (type RGA 3). The gas chromatograph was calibrated independently from the extraction system results by using a single cylinder that was calibrated by NOAA-CMDL in 1996 to have $172 \pm 3 \mathrm{nmole} / \mathrm{mole}$, and applying dynamic dilution downward using zero air. During this calibration by dynamic dilution, two further cylinders with air were fixed in their mixing ratio relative to the dilution line. The three cylinders were then used to assay the five unknown NOAACMDL test standards. Extrapolation was used for the higher concentrations. The results listed in Table 3 show good agreement. There is a discrepancy with the values of NOAA/CMDL obtained 
in 1999 , which indicates a problem with the standards. Such problems were acknowledged (P. Novelli personal communication, 1999) and are treated in a paper in press (K.A. Masarie et al., The NOAA/CSIRO Flask Air Intercomparison Experiment: A strategy for directly assessing consistency among atmospheric measurements derived from independent laboratories, submitted to Journal of Geophysical Research, 2000).

\section{Conclusions}

1. The extraction system has well defined characteristics. The linearity (better than $1 \%$ ), the low detection limit $(<0.2$ nmole/mole), and the quantitative conversion and trapping of the $\mathrm{CO}_{2}$ formed, even in the smallest quantities equivalent to 7 nmole/mole, support the contention that $\mathrm{CO}$ mixing ratios can be determined with an error of less than $1 \%$.

2. The gas chromatography results provide independent evidence for conclusion 1 , assuming that the standard once assayed by NOAA as having $172 \mathrm{nmole} / \mathrm{mole}$ indeed had this value at the moment of the test. This assumption is not unreasonable, but the agreement is possibly coincidental because the standard is a few years old and may have drifted.

3. The intercomparison results for the 1993-1995 ring test systematically reflect the effect of offsets at low mixing ratios. The results from the different laboratories do not allow a conclusion to be made as to which values were correct. There is no independent evidence that the absolute method as used in 1994 produced better results. However, the results of the 1998-1999 ring test show an even stronger trend effect. With the refinement in the absolute method, the test for linearity, and the confirmation by means of gas chromatography, this strongly suggests that the lower end of the NOAA scale has dropped.

4. The results from the absolute method in 1994 and 1999 together suggest that the lowest range NOAA standards actually were already low in 1994 by about $5 \%$.

5. It is recommended that in publications of laboratory intercomparisons of $\mathrm{CO}$ standardization the laboratories involved supply information about zero gas, offsets, standards, and linearity.

Acknowledgments. The authors thank Wolfgang Hanewacker for careful processing and Peter Pohl and lan Hemmingsen for IGNS, New Zealand for developing the pressure gauges. The GC development at NIWA (New Zealand) were carried out by D. C. Lowe and G. Brailsford. We thank Eckehart Scheel for discussions. We particularly thank Paul Novelli for organizing the extensive ring tests, and for critical remarks and discussions. Mark Perri checked the grammar.

\section{References}

Bakwin, P.S., P.P. Tans, and P.C. Novelli, Carbon monoxide budget in the Northem Hemisphere, Geophys. Res. Lett., 21, 433-436, 1994.

Brenninkmeijer, C.A.M., A pneumatically operated high vacuum glass tap, Int. J. Appl. Radiat. Isotop., 32, 679-681, 1981.

Brenninkmeijer, C.A.M., Deuterium, carbon-13 and oxygen-18 in tree and peat deposits in relation to climate, Ph.D. thesis, Univ.of Groningen, Groningen, the Netherlands, 146 pp., 1983.

Brenninkmeijer, C.A.M., Robust, high efficiency, high-capacity cryogenic trap, Anal. Chem., 63, 1182-1184, 1991.

Brenninkmeijer, C.A.M., Measurement of the abundance of ${ }^{14} \mathrm{CO}$ in the atmosphere and the ${ }^{13} \mathrm{C} /{ }^{12} \mathrm{C}$ and ${ }^{18} \mathrm{O} /{ }^{16} \mathrm{O}$ ratio of atmospheric $\mathrm{CO}$, with application in New-Zealand and Antarctica, J. Geophys. Res., 98, 10,595-10,614, 1993.

Brenninkmeijer, C.A.M., and I. Hemmingsen, Sheathed thermocouples used as heater elements, J. Phys. E, Sci. Instrum., 2l, 502-503, 1988.

Brenninkmeijer, C.A.M., and M.C. Louwers, Vacuum actuated highvacuum glass valve, Anal. Chem., 57, 960-962, 1985.

Brenninkmeijer, C.A.M., and T. Röckmann, Russian doll type cryogenic traps: Improved design and isotope separation effects,Anal. Chem., 68, 3050-3053, 1996.

Brenninkmeijer, C.A.M., and T. Röckmann, Principal factors determining the ${ }^{18} \mathrm{O} /{ }^{16} \mathrm{O}$ ratio of atmospheric $\mathrm{CO}$ as derived from observations in the southern hemispheric troposphere and lowermost stratosphere,J. Geophys. Res., 102, 25,477-25,485, 1997.
Brenninkmeijer, C.A.M., and T. Röckmann, Using isotope analysis to improve atmospheric CO budget calculations, in International Symposium on Isotope Techniques in the Study of Past and Current Environmental Changes in the Hydrosphere and the Atmosphere, edited by P. Murphy, pp. 69-77, Int. Atomic Energy Agency, Vienna, Austria, 1998.

Brenninkmeijer, C.A.M., M.R. Manning, D.C. Lowe, R.J. Sparks, G. Wallace, and A. Volz-Thomas, Interhemispheric asymmetry in $\mathrm{OH}$ abundance inferred from measurements of atmospheric ${ }^{14} \mathrm{CO}$, Nature, 356, 50-54, 1992.

Connors, V.S., B.B. Gormsen, S. Nolf, and H.G. Reichle, Spaceborne observations of the global distribution of carbon monoxide in the middle troposphere during April and October 1994, J. Geophys. Res., 104, 21,455-21,470, 1999.

Crutzen, P.J., and P.H. Zimmermann, The changing photochemistry in the troposphere, Tellus, Ser. AB, 43,136-151, 1991.

Jðckel, P., C.A.M. Brenninkmeijer, and M.G. Lawrence, Atmospheric response time of cosmogenic ${ }^{14} \mathrm{CO}$ to changes in solar activity, $J$. Geophys. Res., 105, 6737-6744, 2000.

Krol, M., P.J. van Leeuwen, and J. Lelieveld, Global OH trends inferred from methylchloroform measurements, J. Geophys. Res., 103, 10,697$10,711,1998$.

Mak, J.E., and J.R. Southon, Assessment of tropical OH seasonality using atmospheric ${ }^{14} \mathrm{CO}$ measurements from Barbados, Geophys. Res. Lett., 25, 2801-2814, 1998.

Moxley, J.M., and K.A. Smit, Factors affecting utilisation of atmospheric CO by soils, Soil Biol. Biochem., 30, 65-79, 1998.

Novelli, P.C., CO in the atmosphere: measurements techniques and related issues, Chemosphere Global Change Sc., 1 (1-3), 115-126, 1999.

Novelli, P.C., J.W. Elkins, and L.P. Steele, The development and evaluation of a gravimetric reference scale for measurements of atmospheric carbon monoxide, J. Geophys. Res, 96, 13,109-13,121, 1991.

Novelli, P.C., J.E. Collins Jr., R.C. Myers, G.W. Sachse, and H.E. Scheel, Reevaluation of the NOAA/CMDL carbon monoxide reference scala and comparisons with CO reference gases at NASA Langley and the Fraunhofer Institut, J. Geophys. Res, 99, 12,833-12,839, 1994.

Novelli, P.C. et al., An internally consistent set of globally distributed atmospheric carbon monoxide mixing ratios developed using results from an intercomparison of measurements, $J$. Geophys. Res., 103, 19,258$19,293,1998$ a.

Novelli, P.C., K.A. Masarie, and P.M. Lang, Distribution and recent trends in carbon monoxide in the lower troposphere, $J$ Geophys. Res., 103, 19,015-19,033, $1998 b$.

Prinn, R.G., R.F. Weiss, B.R. Miller, J. Huang, F.N. Alyea, D.M. Cunnald, P.J. Fraser, D.E. Hartley, and P.G. Simmonds, Atmospheric trends and lifetime of $\mathrm{CH}_{3} \mathrm{CCl}_{3}$ and global $\mathrm{OH}$ concentrations, Science, 269, 187$192,1995$.

Quay, P., S. King, D. White, M. Brockington, B. Plotkin, R. Gammon, S. Gerst, and J. Stutsman, Atmospheric (CO)-C-14: A tracer of OH concentration and mixing rates, J. Geophys. Res. 105, 15,147-15,166, 2000.

Reichle, H.G. et al., Space shuttle based global CO measurements during April and October 1994, MAPS instrument, data reduction, and data validation, J. Geophys. Res., 104, 21,443-21,454, 1999.

Rőckmann, T., and C.A.M. Brenninkmeijer, $\mathrm{CO}$ and $\mathrm{CO}_{2}$ isotopic composition in Spitsbergen during the 1995 ARCTOC campaign,Tellus Ser. B, 49, 455-465, 1997.

Sanhueza, E., Y. Dong, D. Scharffe, J.M. Lobert, and P.J. Crutzen, Carbon monoxide uptake by temperate forest soils: The effects of leaves and humus layers, Tellus, Ser. B, 50, 51-58, 1997.

Smiley, W.G., Note on a reagent for oxidation of carbon monoxide, $\mathrm{Nucl}$. Sci. Abstr., 3, 391, 1965.

Stevenis, C.M., and L. Krout, Method for the determination of the concentration and of the carbon and oxygen isotopic composition of atmospheric carbon monoxide, Int. J. Mass Spectrom. Ion Phys., 8, 265-275, 1972.

Volz, A., D.H. Ehhalt, and R.G. Derwent, Seasonal and latitudinal variation of ${ }^{14} \mathrm{CO}$, and the tropospheric concentration of $\mathrm{OH}$ radicals, J. Geophys. Res., 86, 5163-5171, 1981.

M. Bräunlich, C.A.M. Brenninkmeijer,V. Gros, C. Koeppel, T. Rockmann, and D.S. Scharffe, Atmospheric Chemistry Division, Max Planck Institute for Chemistry, D-55020 Mainz, Germany. (carlb@mpchmainz.mpg.de)

(Received February 4, 2000; revised May 9, 2000; accepted May 30, 2000.) 